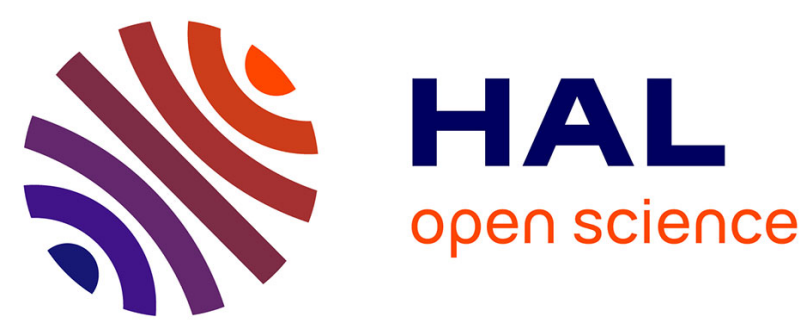

\title{
Soluble Two-Dimensional Covalent Organometallic Polymers by (Arene)Ruthenium-Sulfur Chemistry
}

\author{
Johann Coraux, Wael Hourani, Valentin L Müller, Simon L Lamare, Danial
} Aiman Kamaruddin, Laurence L Magaud, Nedjma L Bendiab, Martien L den Hertog, Olivier L Leynaud, Frank Palmino, et al.

\section{To cite this version:}

Johann Coraux, Wael Hourani, Valentin L Müller, Simon L Lamare, Danial Aiman Kamaruddin, et al.. Soluble Two-Dimensional Covalent Organometallic Polymers by (Arene)Ruthenium-Sulfur Chemistry. Chemistry - A European Journal, 2017, 23 (46), pp.10969. 10.1002/chem.201700054 . hal-01589061

\section{HAL Id: hal-01589061 https://hal.science/hal-01589061}

Submitted on 18 Sep 2017

HAL is a multi-disciplinary open access archive for the deposit and dissemination of scientific research documents, whether they are published or not. The documents may come from teaching and research institutions in France or abroad, or from public or private research centers.
L'archive ouverte pluridisciplinaire HAL, est destinée au dépôt et à la diffusion de documents scientifiques de niveau recherche, publiés ou non, émanant des établissements d'enseignement et de recherche français ou étrangers, des laboratoires publics ou privés. 


\title{
Soluble Two-Dimensional Covalent Organometallic Polymers by (Arene)Ruthenium-Sulfur Chemistry
}

\author{
Johann Coraux, ${ }^{1,2}$ Wael Hourani, ${ }^{3}$ Valentin L. Müller, ${ }^{1,2}$ Simon Lamare, ${ }^{3}$ Danial \\ Aiman Kamaruddin, ${ }^{3}$ Laurence Magaud, ${ }^{1,2}$ Nedjma Bendiab, ${ }^{1,2}$ Martien Den Hertog, ${ }^{1,2}$ \\ Olivier Leynaud, ${ }^{1,2}$ Frank Palmino,${ }^{3}$ Roland Salut,${ }^{3}$ and Frédéric Chérioux ${ }^{3}$, * \\ ${ }^{1}$ CNRS, Inst NEEL, F-38000 Grenoble, France \\ ${ }^{2}$ Univ. Grenoble Alpes, Inst NEEL, F-38000 Grenoble, France \\ ${ }^{3}$ Institut FEMTO-ST, $15 B$ avenue des Montboucons, CNRS, \\ Université Bourgogne Franche-Comté, F-25030 Besancon Cedex, France
}

\begin{abstract}
A class of two-dimensional (2D) covalent organometallic polymers, with nanometer-scale crosslinking, is obtained by arene(ruthenium) sulfur chemistry. Their ambivalent nature, with positively charged crosslinks and lypophylic branches, is the key to the often sought-for and usually hardto-achieve solubility of $2 \mathrm{D}$ polymers in various kinds of solvents. Solubility is here controlled by the planarity of the polymer, which in turn controls Coulomb interactions between the polymer layers. High planarity is achieved for high symmetry crosslinks and short, rigid branches. Owing to their solubility, the polymers are straightforwardly processable, and can be handled as powders, deposited on surfaces by mere spin-coating, or suspended across membranes by drop-casting. The novel 2D materials are potential candidates as flexible membranes for catalysis, cancer therapy, and electronics.
\end{abstract}

Conjugated two-dimensional (2D) materials are ultimately thin species, in which the hoping of charge carriers between neighboring atomic sites governs conduction. Graphene, which may be regarded as a giant conjugated molecule, is a typical example. Its crystalline lattice with two carbon atoms per unit cell yields an unusual electronic conduction. 1 Graphene can be prepared by exfoliation, either in solution ${ }^{2]}$ or mechanically, ${ }_{3}^{[3}$ or from the bottom-up by on-substrate ${ }^{415}$ or total synthesis.6 Rich electronic, magnetic, and optical properties are expected in $2 \mathrm{D}$ materials with more complex structure and composition than graphene. For instance nanopatterning graphene is predicted to yield an electronic band gap,$^{7}$ organometallic compounds featuring a so-called Kagomé lattice are expected to be non-trivial, so-called topological insulators, hosting robust electronic currents at their edges. ${ }^{[}$

The organic synthesis of graphene is limited in size (222 atoms), which is inherent to the so-far explored reactions schemes, relying on the Diels-Alder reaction, cyclotrimerization and cyclodehydrogenation. ${ }^{9}$ Such limitations do not necessarily apply to the other 2D materials. Various strategies yielding extended sheets of mono-molecular thickness, often described as 2D covalent polymers with a high degree of crosslinking, have been reported in the last few years. 10 Synthesis at heterogeneous interfaces, vacuum/solid, 13] 18 air/liquid [19]21,

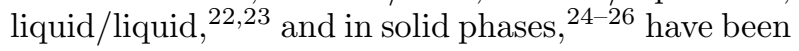
demonstrated indeed. All these methods need to be followed by a transfer or exfoliation process, yield- ing individual layers onto a support of relevance for future applications.

In-solution methods directly producing dispersions of individual flakes are in principle easily processable and for this reason ideally suited to versatile implementation of 2D materials in various applications. The main bottleneck here is the tendency of the individual layers of the 2D polymer to bind together, which inevitably leads to precipitation of the polymer. Precipitation may be avoided (or dispersion may be promoted) thanks to specific solvents, as it was shown for graphene and transition metal dichalcogenides - in this case with polar protic solvents, N-methyl-pyrrolidone and isopropanol ${ }^{[27} \mathrm{An}$ alternative approach is to design layered polymers with covalent intralayer bonds and weakly attractive or even repulsive interlayer interactions, for instance by preventing $\pi-\pi$ interactions ${ }^{28}$, or by exploiting Coulomb repulsion.29]

Here, we report on a novel route to organometallic 2D polymers having high (nanometer-scale) degree of covalent crosslinking. The quantitative, selective, and versatile reaction between Di$\mu$-chlorobis[(arene)chloro ruthenium(II)] and thiophenolato derivatives ${ }^{30 \mid 34}$ (Scheme 1), is demonstrated to lead to sulfur-linked 2D covalent (arene)ruthenium polymers. We find that the planarity of the polymer, which can be optimized with well-chosen monomers, imposes weak interlayer interactions, hence promotes facile dispersion in solution. The solubility of the polymers is intrinsically ambivalent, due to the non-polar, lipophylic 

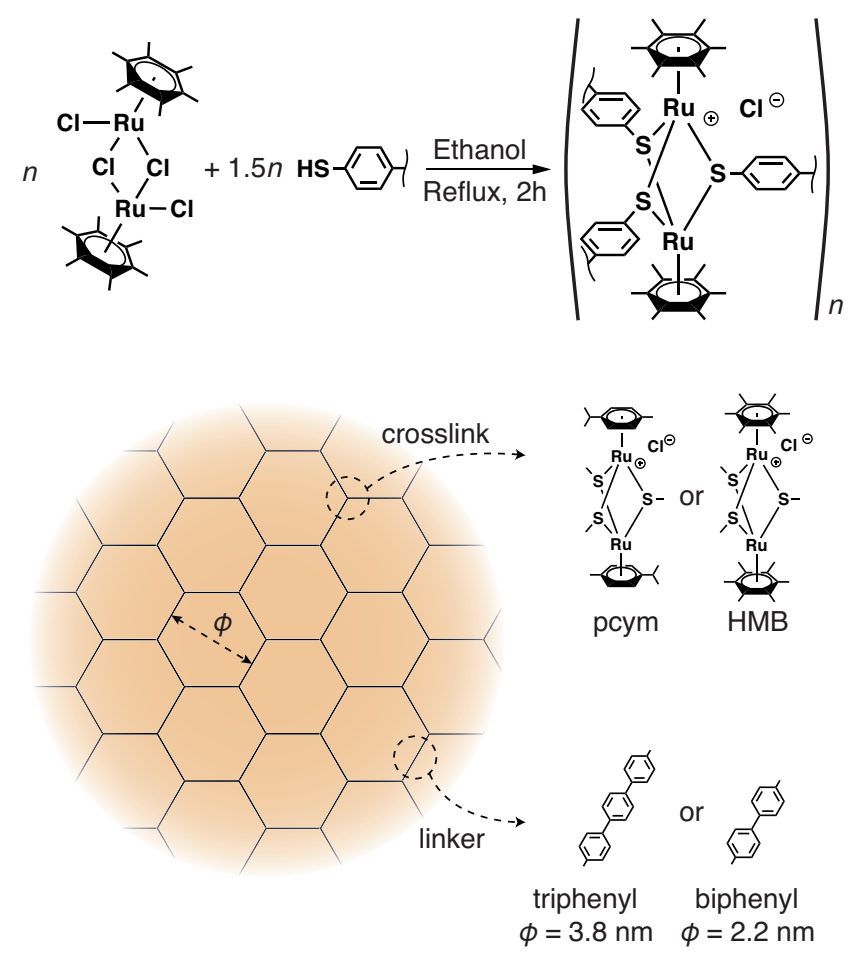

Scheme 1. Schematic Representation of the Formation of Sulfur-Linked 2D Covalent (Arene)Ruthenium Polymers from $\left[\eta^{6}-(\mathrm{pcym}) \mathrm{RuCl}_{2}\right]_{2},\left[\eta^{6}-(\mathrm{HMB}) \mathrm{RuCl}_{2}\right]_{2}$, Dithiophenol-Oligo- $p$-Diphenylene, and Dithiophenol-Oligo- $p$ Terphenylene.

branches and positive charges located about the crosslinks, making them readily dispersed in a variety of solvents, from non-polar to polar protic and aprotic ones. We demonstrate deposition of the monolayered 2D material on highly-oriented pyrolytic graphite (HOPG) by spin-coating, and multilayered suspended thin films by drop-casting onto transmission electron microscopy (TEM) grids by drop-casting.

Synthesis was performed in refluxing ethanol for $1 \mathrm{~h}$, with two kinds of Di- $\mu$-chlorobis[(arene)chloro ruthenium(II)] $\left(\left[\eta^{6}-(\mathrm{HMB}) \mathrm{RuCl}_{2}\right]_{2}\right)$ complexes, differing by the nature of the arene ligand, $p$ cymene (pcym) or hexamethylbenzene (HMB), and of the dithiophenol-oligo- $p$-phenylenes, biphenyl4,4'-dithiol (BPDT) and p-terphenyl-4,4"-dithiol (TPDT). As the reaction of thiophenolato derivatives with Di- $\mu$-chlorobis[(arene)chloro ruthe$\operatorname{nium}(\mathrm{II})]$ is quantitaive, 30 every dinuclear $\mathrm{Ru}$ complex reacts with three thiol groups, yielding a bipyramidal $\mathrm{Ru}_{2} \mathrm{~S}_{3}$ framework coordinated with two arene ligands. The unreacted thiol groups are the active ends of the growing polymer, available for further reaction with other dinuclear Ru complexes. The polymer is composed of positively-charged nodes consisting in S-Ru bipyramids sandwiched by two arenes, and of phenyl chains connecting these nodes. Hexagonal pores are expected to be 2.2 and $3.8 \mathrm{~nm}$ in diameter in the case of the biphenyl and triphenyl linkers respectively.

The polymers are soluble in ethanol during their synthesis, yielding a characteristic transparent orange-colored solution (Figure S1,S2). Therefore, their formation can be monitored by ${ }^{1} \mathrm{H} \mathrm{NMR}$ in deuterated ethanol. Figure 1 a compares the NMR signal corresponding to protons born by the HMB ligand. The upfield shift, from 2.02 (starting unreacted dinuclear Ru complex) to $1.92-1.95$ ppm (reaction product), points to proton shielding associated to an increased charge donated to HMB, which we ascribe to the formation of $\mathrm{Ru}-\mathrm{S}$ bonds. ${ }^{31}$ The presence of three singlets is explained by coexistence of fully and partially reacted precursors and of defects formed upon growth. We note the disappearance of the NMR signal corresponding to thiol protons (i.e. at $3.5 \mathrm{ppm}$ ) during the synthesis (Figure 1 $1 \mathrm{p}$ ). 

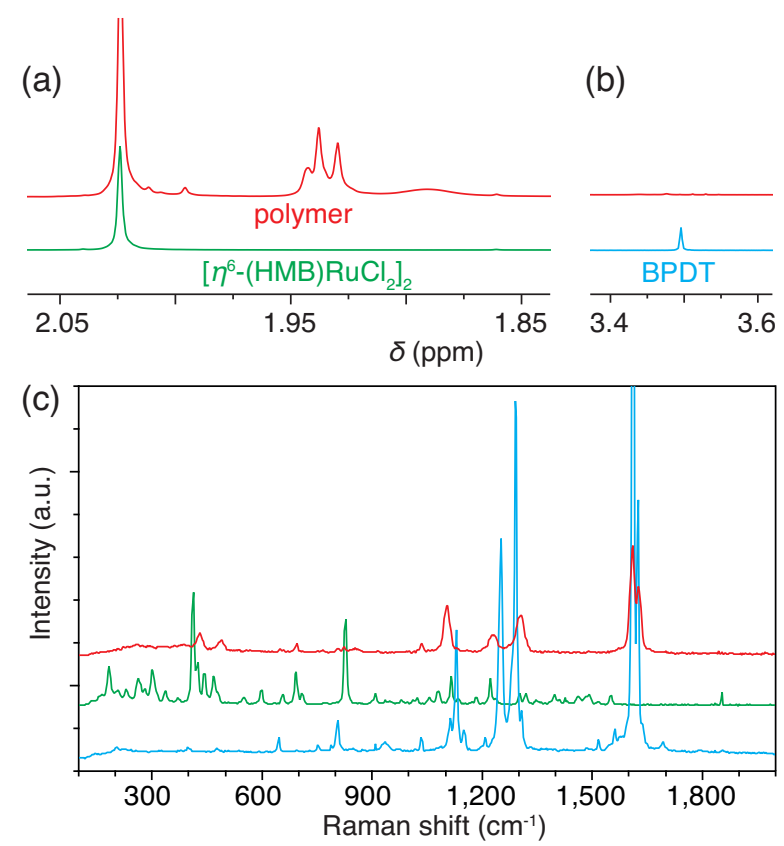

Figure 1. Spectroscopic signature of the formation of the $2 \mathrm{D}$ organometallic polymer. a,b) Partial ${ }^{1} \mathrm{H}$ NMR spectra in different chemical shift ranges $(400 \mathrm{MHz}$, $\mathrm{CDCl}_{3}, 298 \mathrm{~K}$ ) of (a) $\left[\eta^{6}-(\mathrm{HMB}) \mathrm{RuCl}_{2}\right]_{2}$ (green) and the polymer (red), (b) BPDT (blue) and the polymer (red). c) Raman spectra $\left(632 \mathrm{~nm}, 0.06 \mathrm{~mW} / \mu \mathrm{m}^{2}\right)$ of $\left[\eta^{6}-(\mathrm{HMB}) \mathrm{RuCl}_{2}\right]_{2}$ (green), BPDT (blue), and the polymer (red).

After heating, ethanol is evaporated and a purification procedure is used (see Supporting Information) to obtain the polymers in the form of orangered powders, in the gram-scale (Figure 2 a).

The formation and the structure of the polymers are confirmed by Raman spectroscopy and X-ray diffraction, performed on powders of the monomers and of the reaction product.

The Raman spectra of the product of the reaction between the dinuclear Ru-pcym complex and TPBT shows about 10 distinctive features in the range between 150 to $2000 \mathrm{~cm}^{-1}$ (Figure 1p). TPDT shows a characteristic signature in the form of bands between 150 and $350 \mathrm{~cm}^{-1}$, between 550 and $650 \mathrm{~cm}^{-1}$, and at $800 \mathrm{~cm}^{-1}$, corresponding to molecular vibrations

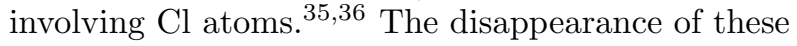
bands translates the departure of $\mathrm{Cl}$ atoms from the covalent framework of the polymer. The bands observed at 415,470 , and $680 \mathrm{~cm}^{-1}$ are characteristic of vibrations involving the arene group and $\mathrm{RuS}$ vibrations, $\frac{37}{37}$ and signal the formation of the nodes of the polymer. Finally, the bands at 1010, 1080, 1210, (a)

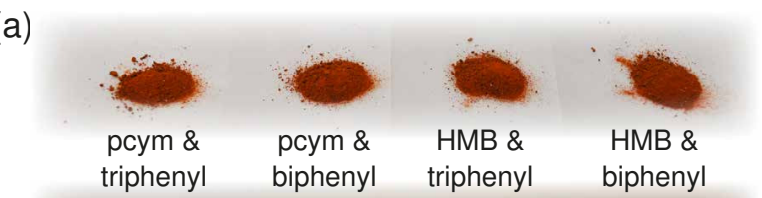

(b)

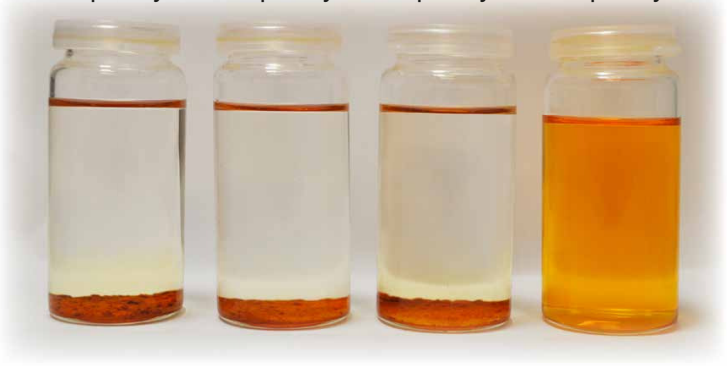

Figure 2. Polymers in powder form and their precipitation or dissolution. a) Photographs of the polymer powders, with (from left to right) pcym ligand and triphenyl linkers, pcym ligand and biphenyl linkers, HMB and triphenyl ligands, and HMB and biphenyl ligands. b) Photographs of precipitated (first to third from left to right) and dissolved powders of the polymers in DMF solvent.

1290, 1595, and $1605 \mathrm{~cm}^{-1}$ are typical of benzene ring and $\mathrm{C}-\mathrm{C}$ vibrations which are expected for the triphenyl branches of the polymer. 38 The benzene ring and $\mathrm{C}-\mathrm{H}$ bending modes at 1080 and $1210 \mathrm{~cm}^{-1}$ respectively are softened compared to TPBT, possibly due to reduced steric hinderance and/or charge transfers in the open polymer structure compared to the packed TPBT powder grains. On the contrary, the C-C stretching mode at $1290 \mathrm{~cm}^{-1}$ is hardened, which we tentatively ascribe to an increased rigidity imposed by the polymeric framework.

The polymers are layered materials, as deduced from X-ray diffraction (Figure S3). Compounds with HMB ligands exhibit one single characteristic interlayer distance, of 1.72 and $1.85 \mathrm{~nm}$ for biphenyl and triphenyl linkers respectively. On the contrary, compounds with pcym ligands reveal two characteristic interlayer distances, 2.03/1.65, and 2.3/1.57 nm for biphenyl and triphenyl linkers respectively. We ascribe the latter bimodal interlayer distance to the above discussed, which is presumably most prominent in case of the longest linkers (triphenyl).

As previouly mentionned, the polymers are isolated as powder after their purification. These powders were tentatively dissolved in various kinds of solvents, ethanol, chloroform, DMF, and DMP. Only in the case of HMB ligands and biphenyl linkers did dissolution happen readily (Figure 2p). For the three other polymers, dissolution was only possible 
after being subjected to ultrasounds, in DMF or DMP solvents, and subsequent centrifugation (see Supporting Information).

(a)
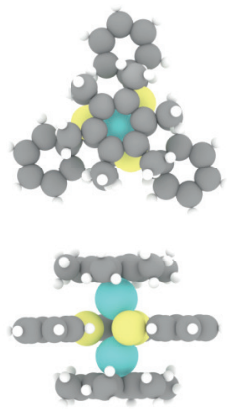

(b)

Flat

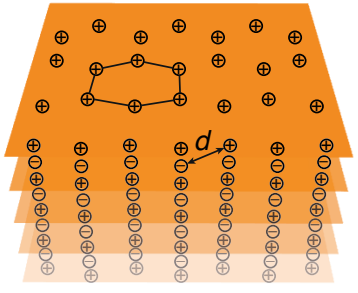

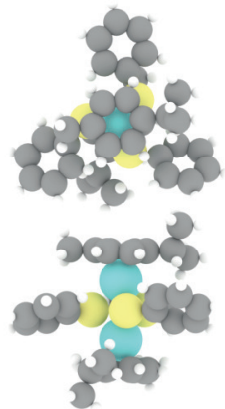

Crumpled

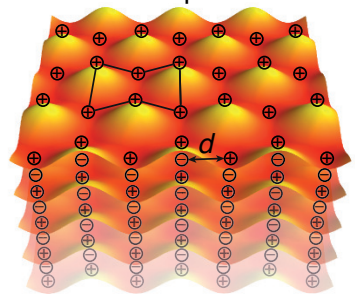

Figure 3. Flat and crumpled topography of the 2D polymers. a) Ball-models representing the optimized structure, as deduced for DFT calculations performed for two segments of a polymer nanopore. Each segment is composed of a linker between two nodes, with HMB (left) and pcym (right) as ligands at the node, and a biphenyl linker. b) Three-dimensional cartoon showing stacks of flat (with flat hexagonal pores) and crumpled (with harmchair hexagonal pores) polymer layers. Positive charge are located at the crosslinks of the polymer, and negative charges $\left(\mathrm{Cl}^{-}\right)$in the immediate vicinity. The distance $d$ between positive and negative charges is smaller for the crumpled polymer.

In order to explain the interlayer distance measured in X-ray diffraction experiments and the different solubilities of polymers, we now consider the topography of the polymers. Density functional theory (DFT) calculations reveal the influence of the symmetry of the arene ligand to this respect, by comparing the simple case of a bipyramid $\mathrm{Ru}_{2} \mathrm{~S}_{3}$ with three phenyl groups attached to $\mathrm{S}$ atoms, with pcym and HMB as arene ligands. The former, which is the least symmetric ligand, favors a non-planar topography, opposite to the later (Figure 3a). The length of the phenyl linker certainly has an influence too, longer linkers (triphenyl vs biphenyl) being more flexible. Overall, a maximum planarity is expected for polymers with HMB arene and biphenyl linkers, while strong crumpling should occur in the

case of pcym arene and triphenyl linkers.

The distinctive propension of the polymers to dissolve in solvents signals distinctive stability of stacks of polymer layers. For such stacks, the cohesion is mainly governed by the Coulomb interactions between positive charges about the crosslinks of the polymers and counter-ions (chloride) in the vicinity. The cohesive energy strongly depends on the spatial distribution of the charges, in turn on the planarity of the 2D polymer layers. As discussed in the Supplementary Information, the cohesive energy is substantially stronger when opposite charges are less distant, as it is the case for a crumpled 2D polymer (Figure 3b).

(a)
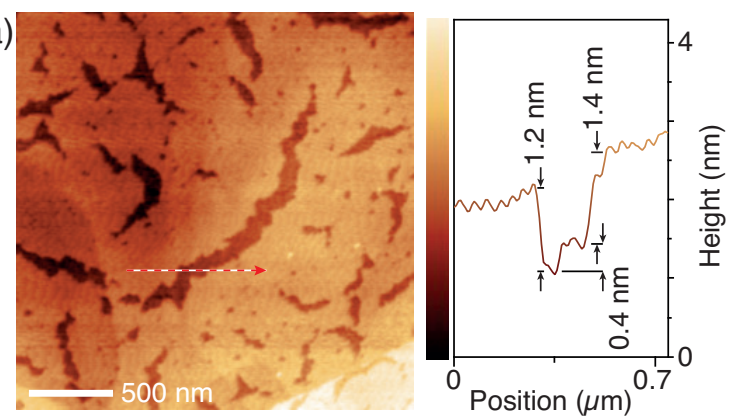

(b)

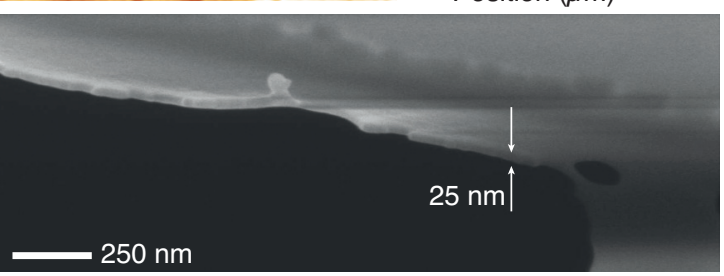

Figure 4. Deposition and suspension of polymer thin films and monolayers. a) Tapping mode AFM topograph of the polymer with HMB ligands and biphenyl linkers, deposited by spin-coating on HOPG, together with the height profile along the dotted line, revealing a HOPG ascending (from left to right) step edge $(0.4 \mathrm{~nm})$, and descending $(1.2 \mathrm{~nm})$ and ascending step edges of the polymer film $(1.4 \mathrm{~nm})$. b) Scanning electron micrograph of drop-casted polymer suspended on a hole in a $\mathrm{Si}_{3} \mathrm{~N}_{4}$ membrane.

Solutions of 2D polymers are especially convenient for versatile deposition onto a variety of supports, as we now show. Spin-coating at the surface of HOPG yields flat surfaces, with the atomically-high step edges of the underlying HOPG still clearly observed in atomic force microscopy (AFM) after deposition. In the case of HMB ligands and biphenyl linkers, the coverage is above $90 \%$, with cracks which we surmise form due to the departure of the solvent. The cracks leave the bare HOPG surface behind, which 
makes it possible to assess the height of the polymer film, typically $1.3 \mathrm{~nm}$ (Figure 4 a), close to the $1 \mathrm{~nm}$ value expected for a single polymer layer. In the case of pcym ligands and triphenyl linkers, the coverage is only partial (Figure S4). As the experimental procedure is easy, we have performed more than 50 experiments in order to determine the height of the adlayer. The height of the polymer surface is $1.4 \pm 0.3 \mathrm{~nm}$, which also matches with the expected thickness of a single polymer layer. The formation of multi-layered thin films was also investigated by drop-casting deposition of a diluted solution of polymers on a TEM grid, which acts as porous substrate (20 $\mu \mathrm{m} \times 2 \mu \mathrm{m}$ rectangular holes (see supporting information). The methods usually yields suspended polymer films with thickness well above the single layer limit, in the range of a few $10 \mathrm{~nm}$ in many instances (Figure $4 \mathrm{~b}$ ).

In summary, we have established arene(ruthenium)-sulfur chemistry as one of the (so far) few strategies towards soluble covalent $2 \mathrm{D}$ polymers. The ambivalent nature of the polymers, charged at their crosslinking nodes and composed of phenly-based linkers, provides them with a good affinity with a variety of solvents. Highest solubilities are obtained for polymers assembled from a well-chosen high-symmetry arene (HMB) and a short thiophenol (biphenyl) leading to rigid linkers. For such polymers a high planarity is expected, which minimizes attractive Coulomb interactions between individual layers of the polymer, preventing precipitation. The polymeric solutions are readily processable, to yield powders, deposition on surfaces (HOPG), and suspension on membranes. More information regarding the molecular and atomic structure of the polymers is needed to characterize the degree of in-plane order of the polymers. Obtaining such information, through high resolution microscopy for instance, is a challenging goal, still rarely achieved for such soft materials prepared at atmospheric conditions. ${ }^{20}$ The specific chemical activity and intrinsic cytotoxicity of arene ruthenium complex ${ }^{39}$ makes the polymers reported here potential candidates as porous sieves of unique functionality, in the view of catalysis and cancer therapy. Besides, their conjugated nature designates them as a novel class of flexible organic conductors, whose transport properties we will address in micro-devices.

\section{ACKNOWLEDGEMENTS}

The authors acknowledge the financial support from the French National Research Agency through contract ORGANI'SO (ANR-15-CE09-0017). This work was partly supported by the french RENATECH network and its FEMTO-ST technological facility. We thank Eric Mossang for fruitful discussions.

\section{KEYWORDS}

2D polymer, organometallic compound, (arene)ruthenium-sulfur chemistry
* frederic.cherioux@femto-st.fr

1 A. H. Castro Neto, F. Guinea, N. M. R. Peres, K. S. Novoselov, and A. K. Geim, Rev. Mod. Phys. 81, 109 (2009).

2 G. Eda, G. Fanchini, and M. Chhowalla, Nat. Nanotechnol. 3, 270 (2008).

3 K. S. Novoselov, A. K. Geim, S. V. Morozov, D. Jiang, Y. Zhang, S. V. Dubonos, I. V. Grigorieva, and A. A. Firsov, Science 306, 666 (2004).

4 J. Coraux, A. T. N'Diaye, C. Busse, and T. Michely, Nano Lett. 8, 565 (2008).

5 X. Li, W. Cai, J. An, S. Kim, J. Nah, D. Yang, R. Piner, A. Velamakanni, I. Jung, E. Tutuc, S. K. Banerjee, and R. S. Ruoff, Science 324, 1312 (2009).

${ }^{6}$ C. D. Simpson, J. D. Brand, A. J. Berresheim, L. Przybilla, H. J. Räder, and K. Müllen, Chem. Eur. J. 8, 1424 (2002).

7 T. G. Pedersen, C. Flindt, J. Pedersen, N. A. Mortensen, A.-P. Jauho, and K. Pedersen, Phys. Rev.
Lett. 100, 136804 (2008).

8 Z. Wang, N. Su, and F. Liu, Nano Lett. 13, 2842 (2013).

${ }^{9}$ L. Chen, Y. Hernandez, X. Feng, and K. Müllen, Angew. Chem. Int. Ed. 51, 7640 (2012).

${ }^{10}$ X. Zhang and Y. Xie, Chem. Soc. Rev. 42, 8187 (2013).

11 C. E. Boott, A. Nazemi, and I. Manners, Angew. Chem. Int. Ed. 54, 13876 (2015).

${ }^{12}$ X. Zhuang, Y. Mai, D. Wu, F. Zhang, and X. Feng, Adv. Mater. 27, 403 (2015).

13 L. Grill, M. Dyer, L. Lafferentz, M. Persson, M. V. Peters, and S. Hecht, Nat. Nanotechnol. 2, 687 (2007).

14 N. A. Zwaneveld, R. Pawlak, M. Abel, D. Catalin, D. Gigmes, D. Bertin, and L. Porte, J. Am. Chem. Soc. 130, 6678 (2008).

15 M. Bieri, M. Treier, J. Cai, K. Aït-Mansour, P. Ruffieux, O. Gröning, P. Gröning, M. Kastler, R. Rieger, X. Feng, K. Müllen, and R. Fasel, Chem. 
Comm. , 6919 (2009)

16 Y.-Q. Zhang, N. Kepčija, M. Kleinschrodt, K. Diller, S. Fischer, A. C. Papageorgiou, F. Allegretti, J. Björk, S. Klyatskaya, F. Klappenberger, M. Ruben, and J. V. Barth, Nat. Commun. 3, 1286 (2012).

17 J. Landers, F. Chérioux, M. De Santis, N. Bendiab, S. Lamare, L. Magaud, and J. Coraux, 2D Materials 1, 034005 (2014).

${ }^{18}$ H. Zhou, J. Liu, S. Du, L. Zhang, G. Li, Y. Zhang, B. Z. Tang, and H.-J. Gao, J. Am. Chem. Soc. 136, 5567 (2014).

19 P. Payamyar, K. Kaja, C. Ruiz-Vargas, A. Stemmer, D. J. Murray, C. J. Johnson, B. T. King, F. Schiffmann, J. VandeVondele, A. Renn, S. Götzinger, P. Ceroni, A. Schütz, L.-T. Lee, Z. Zheng, J. Sakamot, and D. A. Schlüter, Adv. Mater. 26, 2052 (2014).

20 D. J. Murray, D. D. Patterson, P. Payamyar, R. Bhola, W. Song, M. Lackinger, A. D. Schlüter, and B. T. King, J. Am. Chem. Soc. 137, 3450 (2015).

21 W. Dai, F. Shao, J. Szczerbiński, R. McCaffrey, R. Zenobi, Y. Jin, A. D. Schlüter, and W. Zhang, Angew. Chem. Int. Ed. 128, 221 (2016).

${ }^{22}$ T. Kambe, R. Sakamoto, T. Kusamoto, T. Pal, N. Fukui, K. Hoshiko, T. Shimojima, Z. Wang, T. Hirahara, K. Ishizaka, S. Hasegawa, F. Liu, and H. Nishihara, J. Am. Chem. Soc. 136, 14357 (2014).

23 X. Huang, P. Sheng, Z. Tu, F. Zhang, J. Wang, H. Geng, Y. Zou, C.-a. Di, Y. Yi, Y. Sun, W. Xu, and D. Zhu, Nat. Commun. 6, 7408 (2015).

24 P. Kissel, R. Erni, W. B. Schweizer, M. D. Rossell, B. T. King, T. Bauer, S. Götzinger, A. D. Schlüter, and J. Sakamoto, Nat. Chem. 4, 287 (2012).

25 M. J. Kory, M. Wörle, T. Weber, P. Payamyar, S. W. van de Poll, J. Dshemuchadse, N. Trapp, and A. D. Schlüter, Nat. Chem. 6, 779 (2014).
26 P. Kissel, D. J. Murray, W. J. Wulftange, V. J. Catalano, and B. T. King, Nat. Chem. 6, 774 (2014).

27 J. N. Coleman, M. Lotya, A. O'Neill, S. D. Bergin, P. J. King, U. Khan, K. Young, A. Gaucher, S. De, R. J. Smith, I. V. Shvets, K. A. Sunil, G. Stanton, H.Y. Kim, K. Lee, G. T. Kim, G. S. Duesberg, H. Toby, J. J. Boland, J. J. Wang, J. F. Donegan, J. C. Grunlan, G. Moriarty, A. Shmeliov, R. J. Nicholls, J. M. Perkins, E. M. Grieveson, K. Theuwissen, D. W. McComb, P. D. Nellist, and V. Nicholosi, Science 331, 568 (2011).

${ }^{28}$ K. Baek, G. Yun, Y. Kim, D. Kim, R. Hota, I. Hwang, D. Xu, Y. H. Ko, G. H. Gu, J. H. Suh, C. G. Park, B. J. Sung, and K. Kim, J. Am. Chem. Soc. 135, 6523 (2013).

29 T.-Y. Zhou, F. Lin, Z.-T. Li, and X. Zhao, Macromolecules 46, 7745 (2013).

30 F. Chérioux, C. M. Thomas, B. Therrien, and G. Süss-Fink, Chem. Eur. J. 8, 4377 (2002).

31 F. Chérioux, C. M. Thomas, T. Monnier, and G. Süss-Fink, Polyhedron 22, 543 (2003).

32 F. Chérioux, B. Therrien, and G. Süss-Fink, Inorg. Chim. Acta 357, 834 (2004).

33 F. Chérioux, B. Therrien, C. Comminges, and G. Süss-Fink, J. Organomet. Chem. 690, 2365 (2005).

34 M. Gras, B. Therrien, G. Süss-Fink, O. Zava, and P. J. Dyson, Dalton Trans. 39, 10305 (2010).

35 D. Lin-Vien, N. B. Colthup, W. G. Fateley, and J. G. Grasselli, The handbook of infrared and Raman characteristic frequencies of org (Elsevier, 1991).

36 T. Opstal, K. Melis, and F. Verpoort, Catal. Lett. 74, 155 (2001).

37 R. Armstrong, M. Aroney, C. Barnes, and K. Nugent, J. Mol. Struct. 323, 15 (1994).

38 E.-O. Ganbold and S.-W. Joo, Bull. Korean Chem. Soc. 36, 887 (2015).

39 G. Süss-Fink, J. Organomet. Chem. 751, 2 (2014). 